\title{
Quantitative Characteristics of the Current Multi-Source Precipitation Products over Zhejiang Province, in Summer, 2019
}

\author{
Chao Qiu ${ }^{1}$, Leiding Ding ${ }^{2}$, Lan Zhang ${ }^{3}$, Jintao $\mathrm{Xu}^{4}$ (D) and Ziqiang Ma ${ }^{4, *(D)}$ \\ 1 Zhejiang Province Hydrology Management Center, Hangzhou 310009, China; qiuchao@zjwater.gov.cn \\ 2 College of Big Data and Information Engineering, Guizhou University, Guiyang 550025, China; \\ gs.ldding18@gzu.edu.cn \\ 3 Zhejiang Ecological and Environmental Monitoring Center, Hangzhou 310009, China; \\ zhaolanlan@mwr.gov.cn \\ 4 Institute of Remote Sensing and Geographical Information Systems, School of Earth and Space Sciences, \\ Peking University, Beijing 100871, China; jintaox@zju.edu.cn \\ * Correspondence: ziqma@pku.edu.cn; Tel.: +86-188-0653-4289
}

Citation: Qiu, C.; Ding, L.; Zhang, L.; Xu, J.; Ma, Z. Quantitative Characteristics of the Current Multi-Source Precipitation Products over Zhejiang Province, in Summer, 2019. Water 2021, 13, 334. https:// doi.org/10.3390/w13030334

Academic Editor: Thomas Meixner Received: 12 December 2020

Accepted: 23 January 2021

Published: 29 January 2021

Publisher's Note: MDPI stays neutral with regard to jurisdictional claims in published maps and institutional affiliations.

Copyright: (c) 2021 by the authors. Licensee MDPI, Basel, Switzerland. This article is an open access article distributed under the terms and conditions of the Creative Commons Attribution (CC BY) license (https:// creativecommons.org/licenses/by/ $4.0 /)$.

\begin{abstract}
Precipitation data with fine quality plays vital roles in hydrological-related applications. In this study, we choose the high-quality China Merged Precipitation Analysis data (CMPA) as the benchmark for evaluating four satellite-based precipitation products (PERSIANN-CCS, FY4A QPE, GSMap_Gauge, IMERG-Final) and one model-based precipitation product (ERA5-Land), respectively, at $0.1^{\circ}$, hourly scales over the Zhejiang province, China, in summer, from June to August 2019. The main conclusions were as follows-(1) all other products demonstrate similar patterns with CMPA ( $\sim 325.60 \mathrm{~mm} / \mathrm{h}$, std $\sim 0.07 \mathrm{~mm} / \mathrm{h})$, except FY4A QPE $(\sim 281.79 \mathrm{~mm} / \mathrm{h}$, std $\sim 0.18 \mathrm{~mm} / \mathrm{h})$, while, overall, the PERSIANN-CCS underestimates the precipitation against CMPA with a mean value around $236.29 \mathrm{~mm} / \mathrm{h}$ (std $\sim 0.06 \mathrm{~mm} / \mathrm{h}$ ), and the ERA5-Land, GSMap_Guage, and IMERG-Final generally overestimate the precipitation with a mean value around $370.00 \mathrm{~mm} / \mathrm{h}$ (std $\sim 0.06 \mathrm{~mm} / \mathrm{h}$ ). (2) The GSMap_Gauge outperforms IMERG-Final against CMPA with CC $\sim 0.50$ and RMSE $\sim 1.51 \mathrm{~mm} / \mathrm{h}$, and CC $\sim 0.48$ and RMSE $\sim 1.64 \mathrm{~mm} / \mathrm{h}$, respectively. (3) The PERSIANN-CCS significantly underestimates the precipitation $(\mathrm{CC} \sim 0.26$, bias $\sim-35.03 \%$, RMSE $\sim 1.81 \mathrm{~mm} / \mathrm{h}$, probability of detection, POD, $\sim 0.33$, false alarm ratio, FAR, $\sim 0.47$ ), potentially due to its weak abilities to capture precipitation events and estimate the precipitation. (4) Though ERA5-Land has the best ability to capture precipitation events (POD $\sim 0.78$ ), the largest misjudgments (FAR $\sim .54$ ) result in its great uncertainties with CC $\sim 0.39$, which performs worse than those of GSMap_Gauge and IMERG-Final. (5) The ranking of precipitation products, in terms of the general evaluation metrics, over Zhejiang province is GSMap_Gauge, IMERG-Final, ERA5-Land, PERSIANN-CCS, and FY4A QPE, which provides valuable recommendations for applying these products in various related application fields.
\end{abstract}

Keywords: precipitation; evaluation; satellite-based precipitation products; reanalysis precipitation product; CMPA; Zhejiang province

\section{Introduction}

Precipitation plays critical roles in the global water cycles and gridded precipitation data with fine quality is greatly needed in various application fields, such as hydrological models, and climate research [1-5]. Currently, there are three main manners for obtaining rain information, e.g., rain gauge stations, ground-based weather radars, satellite-based sensors [6-9]. However, measuring precipitation by rain gauges is easily limited by the number of ground stations, especially over remote regions, e.g., the Tibetan Plateau [1-3], and the beams of ground-based weather radars are also obscured by the mountains, which is relatively more suitable for plain areas, therefore, the ground-based weather radars could not provide spatio-temporal continuous precipitation observations on a global scale [10]. 
Over the past five decades, remotesensing techniques and satellite-based precipitation retrieval algorithms improved greatly [11]. A series of satellite-based precipitation products with various spatio-temporal resolutions were developed. For example, the PERSIANN-CCS (for the details of the abbreviations, please see Table 1) [12,13], FY4A QPE [14], GSMap_Gauge [15], and IMERG-Final [16-18]. In addition, reanalysis precipitation products were also more and more popular, and even outperformed satellite-based precipitation products in some regions.

Various studies explored the qualities of these satellite-based and model-based precipitation datasets against ground observations at regional scales. For instance, Lu et al. [19] evaluated the accuracy of IMERG against rain gauge data in 2017 over the YunnanKweichow Plateau, China, and found that IMERG could capture large-scale rainfall distributions, but had weak abilities in detecting the precipitation events, resulting in significant overestimations. Meanwhile, Xu et al. [20] also found that IMERG had overestimated the precipitation by about $12 \%$ through assessments on IMERG from June to August 2018, at an hourly scale, over Mainland China. Nevertheless, IMERG demonstrated reasonable qualities at daily and seasonal temporal scales in the Mexican region [21]. As for PERSIANN-CCS, it could generally capture the spatiotemporal patterns and the timings of the diurnal convective rainfall events, while the elevation-dependent biases existed, which brought great uncertainties for the qualities of PERSIANN-CCS, e.g., in the complex terrain region of Northwestern Mexico [12]. In terms of GSMap, Fu et al. [22] concluded that it underestimated precipitation against the gauge-based precipitation measurements across the Poyang Lake Basin. Among the model-based precipitation datasets, the quality of the latest generation of ERA5 was greatly improved, as compared to those of previous versions, e.g., ERA-Interim, which even outperformed the Tropical Rainfall Measuring Mission (TRMM) Multi-satellite Precipitation Analysis (TMPA) in some regional areas [23].

However, there was almost no investigation of precipitation products in Zhejiang, China, especially the evaluation for Chinese FY4 series satellite precipitation products. As one of the most exposed regions to the extreme rainfall events and floods, it is great meaningful to characterize the quality of the most popular precipitation datasets, especially in the emergence of the FY4 QPE. Therefore, this paper aimed at assessing five precipitation products (PERSIANN-CCS, ERA5-Land, FY4A QPE, GSMap_Gauge, and IMERG-Final) against CMPA, in terms of the amounts, and the occurrences of the precipitation events at $0.1^{\circ}$ and hourly scales, over the Zhejiang province, in summer of 2019.

\section{Study Area and Materials}

\subsection{Study Area}

Zhejiang province $\left(27^{\circ} 02^{\prime}-31^{\circ} 11^{\prime} \mathrm{N}\right.$ and $\left.118^{\circ} 01^{\prime}-123^{\circ} 10^{\prime} \mathrm{E}\right)$ is located in Southeastern China along the East Sea, with elevation varying from 0 to $1800 \mathrm{~m}$ (shown in Figure 1), with an area of around $105 \mathrm{~km}^{2}$, of which the mountainous regions account for $\sim 74.63 \%$. Generally, the Zhejiang province is mainly controlled by the East Asian Monsoon climate, with unevenly distributed precipitation varying from $1200 \mathrm{~mm} /$ year to $2000 \mathrm{~mm}$ /year, and $70 \%$ of the annual rainfall is concentrated in the rainy season, from April to September, which easily results in extreme flood disasters [24]. 


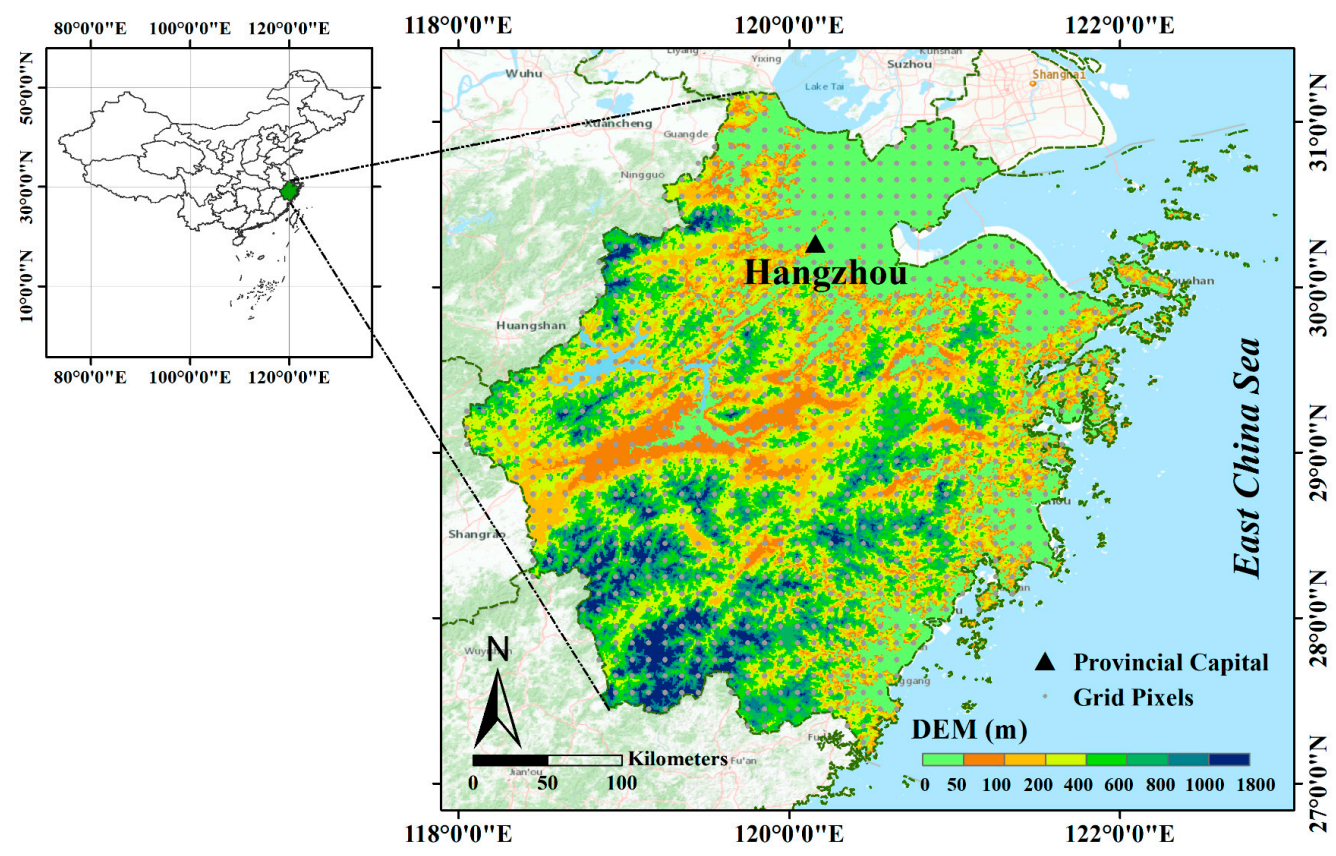

Figure 1. Spatial patterns of digital elevation model (DEM) over the Zhejiang province, China.

\section{2. $C M P A$}

The China Merged Precipitation Analysis (CMPA, $0.1^{\circ} /$ hourly) was produced by merging hourly rain gauge data, from $>30,000$ automatic weather stations in China, and the microwave-based CMORPH precipitation dataset, which was provided by the National Meteorological Information Center of the China Meteorological Administration (http: / / data.cma.cn) [25]. First, CMORPH data $(8 \mathrm{~km}, 30 \mathrm{~min})$ were resampled into those at finer resolutions $\left(0.1^{\circ}, 1 \mathrm{~h}\right)$. Then, the optimal interpolation method was used to predict the gridded precipitation pattern based on gauge observations with corresponding interpolated CMORPH data, and the result was called CMPA [26]. The quality of CMPA was mainly affected by the gauge densities, which meant it could be used as the benchmark over Eastern China, e.g., the Zhejiang province, to evaluate the satellite-based and model-based precipitation estimates.

\subsection{Satellite-Based and Model-Based Precipitation Products}

Detailed information of the four satellite-based (IMERG-Final, GSMap_Gauge, PERSIANN-CCS, FY4A QPE) and one model-based (ERA5-Land) precipitation products are listed in Table 1. For instance, the IMERG-Final dataset is a level 3 precipitation product in the GPM era, which was calibrated on the basis of the monthly gauge analysis dataset, and it could be obtained through NASA from the website: https://pmm.nasa.gov/dataaccess / downloads/gpm. Meanwhile, the GSMap products is also a popular microwavebased precipitation product, and was calibrated using gauge analysis at a daily scale, which could be acquired through the website: https://sharaku.eorc.jaxa.jp/GSMap/index.htm. As for the PERSIANN-CCS, it was generated based on local and regional cloud features from infrared observations aboard geostationary satellites at the bands $\sim 10.7 \mu \mathrm{m}$, which was characterized by finest resolutions $\left(0.04^{\circ}\right.$ and $\left.30 \mathrm{~min}\right)$ among the current satellitebased precipitation product, and PERSIANN-CCS can also easily be downloaded through http:/ / chrs.web.uci.edu/SP_activities01.php. The Fengyun 4 (FY4) are the second generation of geostationary meteorological satellite launched by China, following the Fengyun 2 series, and FY4A represents the first satellite of the Fengyun 4 series, which provides 32 estimates, including Quantitative Precipitation Estimation (QPE). FY4A QPE (4 km, $30 \mathrm{~min}$ ) could be acquired from National Satellite Meteorological Center (NSMC), China (www.nsmc.org.cn). The PERESIANN-CCS and FY4A QPE were linearly resampled to 
those $\left(0.1^{\circ}\right)$, and accumulated to hourly rainfall estimates, to be consistent with the resolutions of CMPA datasets. As for the model-based precipitation estimates, the latest version of ERA from the European Centre for Medium-Range Weather Forecast (ECMWF), ERA5Land, was used in this study by considering its quality and resolutions $\left(0.1^{\circ}, 1\right.$ hourly), which could be obtained from the website: https://cds.climate.copernicus.eu/cdsapp\#!/ dataset/10.24381/cds.e2161bac?tab=form.

Table 1. Summary of satellite-based and reanalysis precipitation datasets used in this study.

\begin{tabular}{ccccc}
\hline Dataset & Full Name of the Dataset & Resolution & Period & Reference \\
\hline PERSIANN-CCS & $\begin{array}{c}\text { Precipitation Estimation from } \\
\text { Remotely Sensed Information using } \\
\text { Artificial Neural Networks-Cloud } \\
\text { Classification System }\end{array}$ & $0.04^{\circ}, 0.5$ hourly & 2006-present & Hong et al. [27] \\
\hline ERA5-Land & $\begin{array}{c}\text { European Centre for Medium-Range } \\
\text { Weather Forecasts Reanalysis5-Land }\end{array}$ & $0.10^{\circ}, 1$ hourly & 1979-present & Hoffmann et al. [28] \\
\hline FY4A QPE & $\begin{array}{c}\text { Fengyun 4A } \\
\text { QuantitativePrecipitation Estimation }\end{array}$ & $0.04^{\circ}, 0.5$ hourly & 2018-present & Shen et al. [25] \\
\hline GSMap_Gauge & $\begin{array}{c}\text { Global Satellite Mapping } \\
\text { ofPrecipitation-Gauge }\end{array}$ & $0.10^{\circ}, 1$ hourly & 2000-present & Mega et al. [29] \\
\hline IMERG-Final & $\begin{array}{c}\text { Integrated Multi-Satellite Retrievals } \\
\text { for Global Precipitation } \\
\text { Measurement-Final }\end{array}$ & $0.10^{\circ}, 1$ hourly & 2000-present & Huffman et al. [18] \\
\hline
\end{tabular}

\section{Methods}

A classical combination of statistical metrics was adopted to assess the qualities of the gridded precipitation data against ground observations; these are listed in Table $2[30,31]$. In terms of the errors between estimates and ground observations, three classical metrics were widely applied, which included CC, Bias, RMSE. As for evaluating the capabilities to correctly capture the rainfall events, there were also three indices, including POD, FAR, and CSI. CSI is a comprehensive index to consider both correct hit (POD) and false alarm (FAR) [32]. In this study, the thresholds of $0.1 \mathrm{~mm} / \mathrm{h}$ were used for discriminating the rainfall events. Overall, all these indices should be comprehensively considered when concluding the qualities of the precipitation estimates.

Table 2. List of the validation statistical metrics for evaluating satellite-based precipitation products in the study.

\begin{tabular}{ccc}
\hline Statistic Index & Formula & Best Value \\
\hline Correlation coefficient (CC) & $\mathrm{CC}=\sqrt{\frac{\sum_{\mathrm{i}=1}^{\mathrm{n}}\left(\mathrm{O}_{\mathrm{i}}-\overline{\mathrm{O}}\right)^{2}\left(\mathrm{P}_{\mathrm{i}}-\overline{\mathrm{P}}\right)^{2}}{\sum_{\mathrm{i}=1}^{\mathrm{n}}\left(\mathrm{O}_{\mathrm{i}}-\overline{\mathrm{O}}\right)^{2} \times \sum_{\mathrm{i}=1}^{\mathrm{n}}\left(\mathrm{P}_{\mathrm{i}}-\overline{\mathrm{P}}\right)^{2}}}$ & 1 \\
\hline Relative bias (bias) & bias $=\frac{\sum_{\mathrm{i}=1}^{\mathrm{n}}\left(\mathrm{P}_{\mathrm{i}}-\mathrm{O}_{\mathrm{i}}\right)}{\sum_{\mathrm{i}=1}^{\mathrm{O}} \mathrm{O}_{\mathrm{i}}} \times 100 \%$ & 0 \\
\hline Root mean square error (RMSE) & $\mathrm{RMSE}=\sqrt{\frac{1}{n} \sum_{\mathrm{i}=1}^{\mathrm{n}}\left(\mathrm{P}_{\mathrm{i}}-\mathrm{O}_{\mathrm{i}}\right)^{2}}$ & 1 \\
\hline Probability of detection (POD) & $\mathrm{POD}=\frac{\mathrm{H}}{\mathrm{H}+\mathrm{M}}$ & 0 \\
\hline False alarm ratio (FAR) & $\mathrm{FAR}=\frac{\mathrm{F}}{\mathrm{H}+\mathrm{F}}$ & 1 \\
\hline Critical success index (CSI) & $\mathrm{CSI}=\frac{\mathrm{H}}{\mathrm{H}+\mathrm{M}+\mathrm{F}}$ & 1 \\
\hline
\end{tabular}

Notation: $\mathrm{O}_{\mathrm{i}}$ the amount of precipitation observed by the CMPA data; $\overline{\mathrm{O}}$, the average values of CMPA, $\mathrm{P}_{\mathrm{i}}$, the values of the estimates; $\overline{\mathrm{P}}$, the average estimated precipitation; $n$, the number of precipitation pairs of CMPA data and the corresponding estimates; $\mathrm{H}$, observed precipitation event correctly detected by the estimates; $\mathrm{M}$, observed precipitation event not detected by estimates; $\mathrm{F}$, precipitation event detected by estimates but not observed. 


\section{Results}

\subsection{Spatial Distributions of the Precipitation over Zhejiang Province in Summer}

Figure 2 shows the spatial distributions of total precipitation, in summer, from June to August 2019, over the Zhejiang province, based on CMPA, PERSIANN-CCS, ERA5-Land, FY4A QPE, GSMap_Gauge, and IMERG-Final. The precipitation was relatively large in the eastern coastal area and southwest mountain area of the Zhejiang province (Figure 2a). Compared to the CMPA, the PERSIANN-CCS underestimated precipitation with volumes smaller than $800 \mathrm{~mm}$ (Figure 2b). Additionally, the FY4A QPE underestimated precipitation in the north $(<500 \mathrm{~mm})$, while it significantly overestimated precipitation in the south $(>1000 \mathrm{~mm}$ ). In terms of the spatial patterns, FY4A QPE could not capture the distributions very well, compared to other precipitation products, e.g., overestimating and underestimating the precipitation volumes in the northern and southern regions, respectively (Figure 2d). Compared to CMPA, ERA5-Land overestimated the precipitation amount in most parts of the Zhejiang province (Figure 2c), while GSMap_Gauge and IMERG-Final overestimated the precipitation by around $200 \mathrm{~mm}$ (Figure 2e,f).

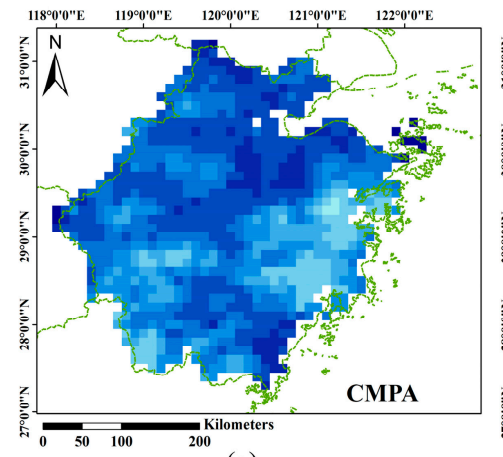

(a)

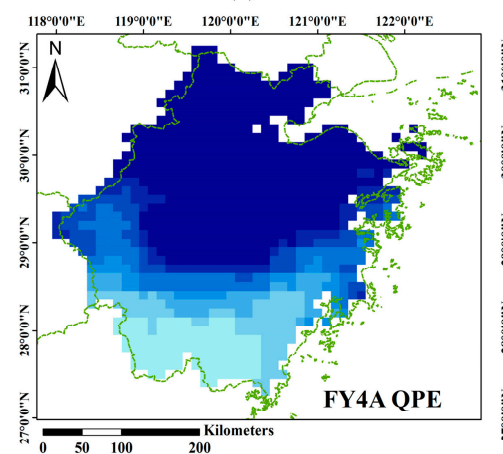

(d)

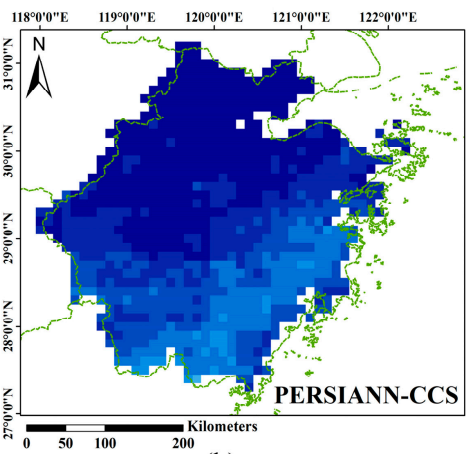

(b)

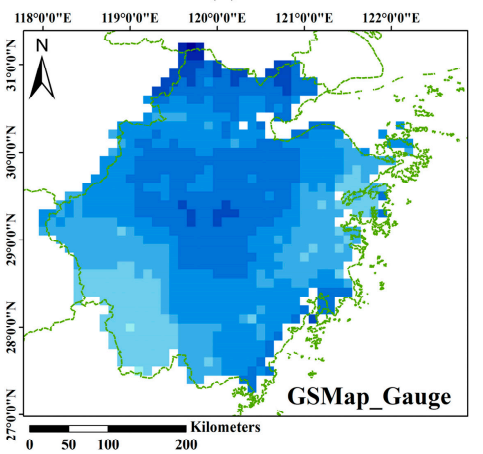

(e)

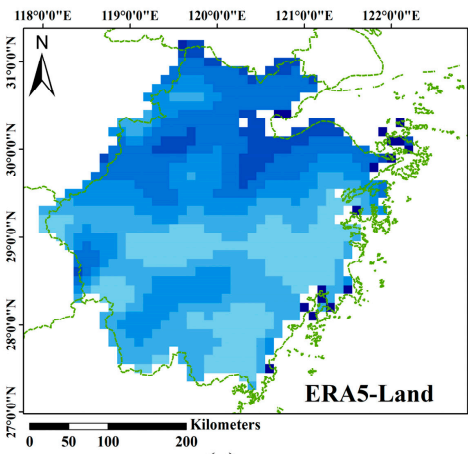

(c)

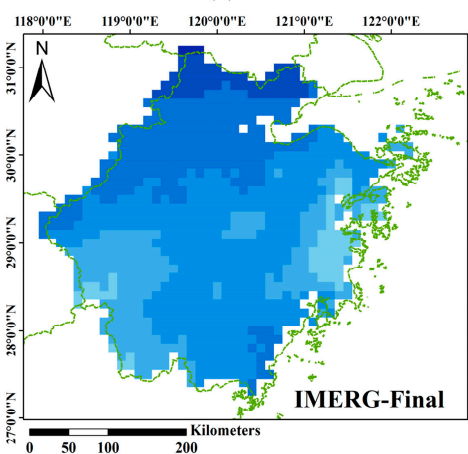

(f)

Summer Precipitation (mm)

$\begin{array}{lllllll}500 & 600 & 700 & 800 & 900 & 1000 & 1300\end{array}$

Figure 2. Spatial patterns of total precipitation based on (a) CMPA, (b) PERSIANN-CCS (c) ERA5-Land, (d) FY4A QPE (e) GSMap_Gauge, and (f) IMERG-Final over the Zhejiang province in summer, from June to August 2019.

\subsection{Spatial Patterns of Evaluations on the Precipitation Products and CMPA Data at an Hourly Scale}

Figure 3 shows the spatial distributions of CC of PERSIANN-CCS, ERA5-Land, FY4A QPE, GSMap_Gauge, and IMERG-Final against the CMPA data, respectively, at $0.1^{\circ}$ and hourly scales over the Zhejiang province, in the summer of 2019. Overall, the differences in spatial distributions of $C C$ among precipitation products were significant. In terms of CC, it was obvious that the GSMap_Gauge and IMERG-Final outperformed others, overall. However, FY4A QPE showed the smallest CC values, most of which were smaller than 0.3 and even 0.1 over some areas in the Northern and Eastern Zhejiang (Figure 3c). The CC values of PERSIANN-CCS were slightly larger than those of FY4A QPE, especially in the 
south (Figure 3a). Generally, the CC values of ERA5-Land against CMPA were between 0.1 and 0.6, with a decreasing trend from north to south (Figure 3b). GSMap_Gauge correlated well with CMPA data, with CC values larger than 0.5 over most regions, though over some small regions in the south CC values were smaller than 0.3 (Figure 3d). The spatial distributions of CC values of IMERG-Final and GSMap_Gauge were similar, and most of the CC values were larger than 0.4 (Figure 3e).

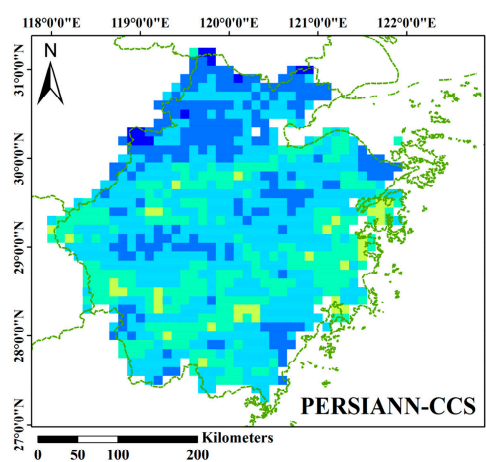

(a)

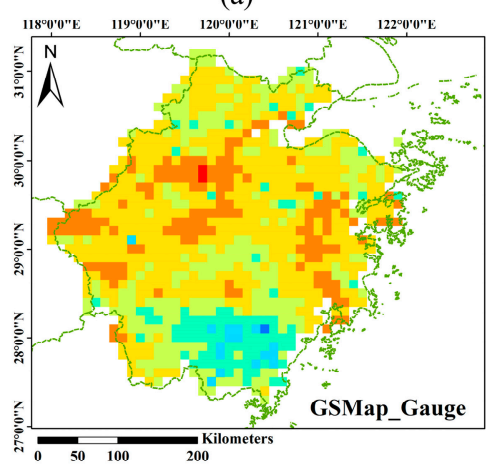

(d)

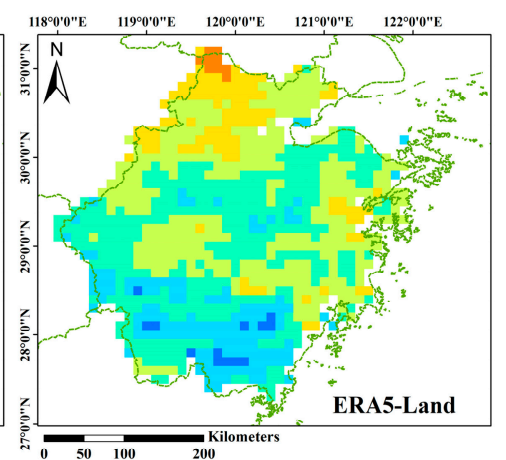

(b)

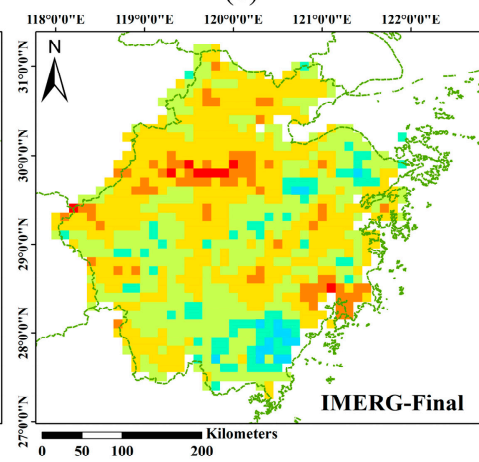

(e)

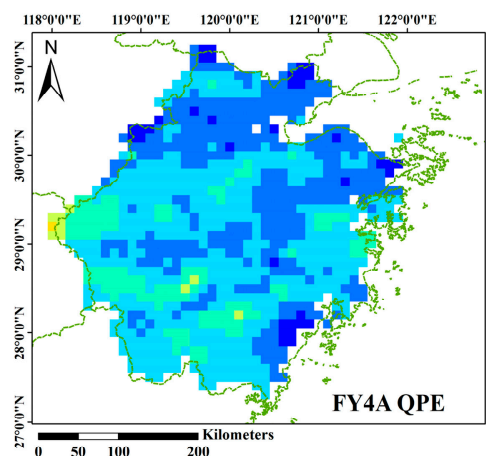

(c)

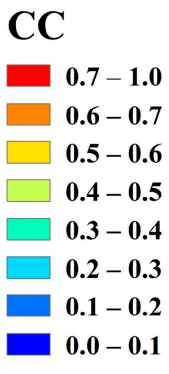

Figure 3. Spatial patterns of CC based on (a) PERSIANN-CCS (b) ERA5-Land, (c) FY4A QPE (d) GSMap_Gauge, and (e) IMERG-Final against CMPA at an hourly scale over the Zhejiang province in summer, from June to August 2019.

Figure 4 demonstrates the spatial patterns of the performances on the five precipitation products, in terms of bias, against CMPA data, at an hourly scale and $0.1^{\circ} \times 0.1^{\circ}$ resolution, over the Zhejiang province, in the summer of 2019. The bias values of PERSIANN-CCS were smaller than $-10 \%$ over half of the Zhejiang province, where it was significantly lower than $-30 \%$ (Figure $4 \mathrm{a}$ ), especially in the northern area. The bias values of FY4A QPE were almost larger than $60 \%$ in the Southern Zhejiang province and were almost smaller than $-50 \%$ in north. The spatial patterns of bias underlined that FY4A QPE cannot capture the spatial characteristics of precipitation (Figure 4c). Meanwhile, the ERA5Land, GSMap_Gauge, and IMERG-Final tend to overestimate precipitation from an overall perspective, while both positive and negative biases exist, with the bias values varying from $-30.00 \%$ to $30.00 \%$. Figure $4 \mathrm{~b}$ also indicates that the ERA5-Land overestimates the magnitude of precipitation especially in the central and southern regions. On the contrary, the GSMap_Gauge overestimated the precipitation in the surrounding area (Figure 4d). Additionally, the spatial distributions of the bias of IMERG-Final and ERA5-Land were similar (Figure 4e).

Figure 5 shows the spatial distributions of RMSE of five precipitation products against CMPA, at an hourly scale, over the Zhejiang province, in summer, from June to August 2019. It was obvious that FY4A QPE showed the largest RMSE $(>2.0 \mathrm{~mm} / \mathrm{h}$ in the Southern Zhejiang province), followed by the PERSIANN-CCS (Figure 4a,c). While the RMSE values of the GSMap_Gauge were slightly smaller than those of IMERG-Final and ERA5Land, at the corresponding regions (Figure $4 \mathrm{~b}, \mathrm{~d}, \mathrm{e}$ ). Considering CC, bias and RMSE, 
GSMap_Gauge outperformed other precipitation products and FY4A QPE seemed to have the lowest qualities.

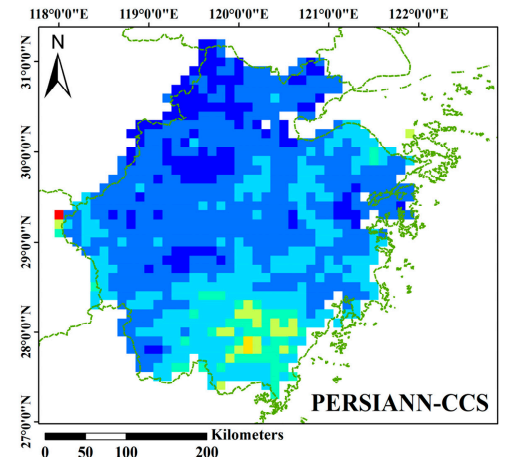

(a)

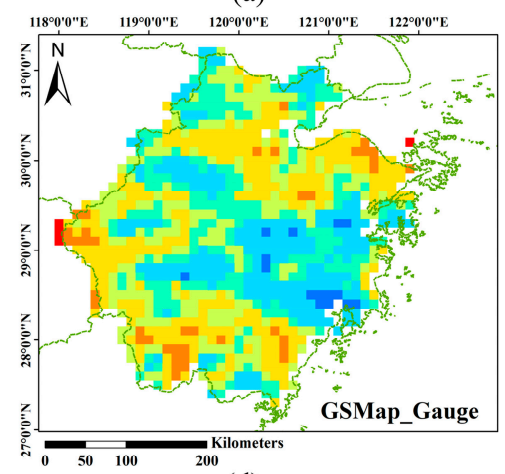

(d)

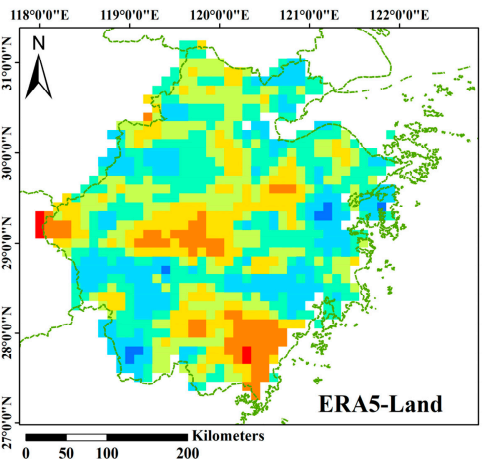

(b)

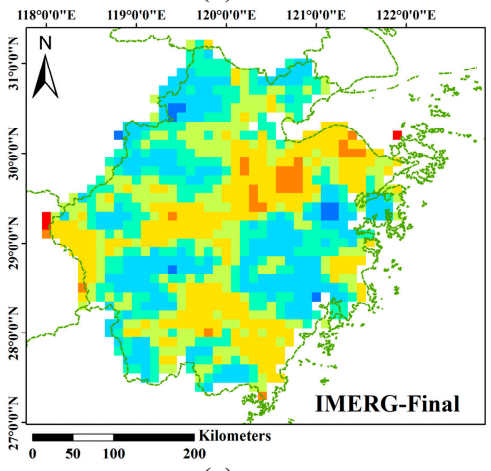

(e)

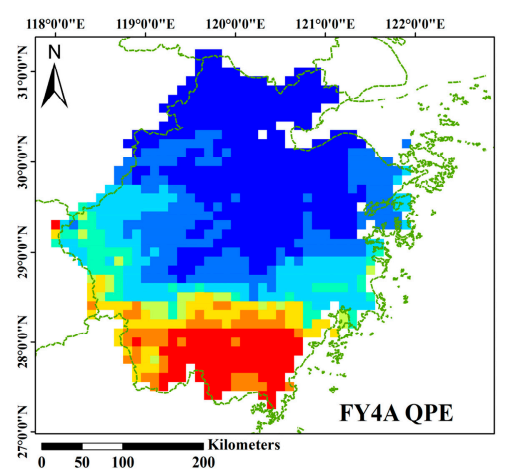

(c)

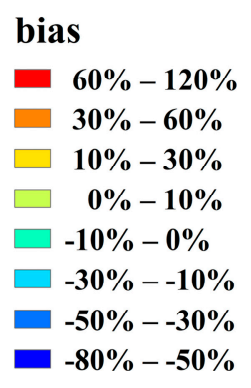

Figure 4. Spatial patterns of bias based on (a) PERSIANN-CCS (b) ERA5-Land, (c) FY4A QPE (d) GSMap_Gauge, and (e) IMERG-Final against CMPA, at an hourly scale over the Zhejiang province in summer, from June to August 2019.

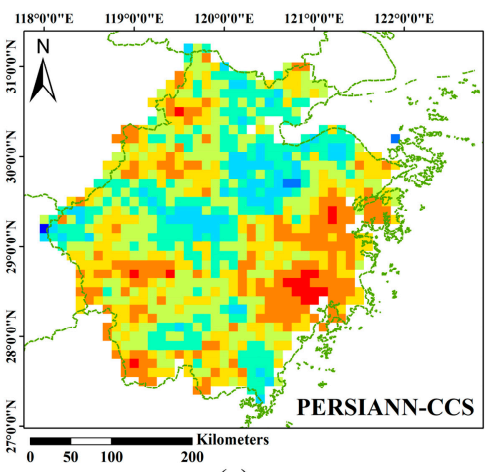

(a)

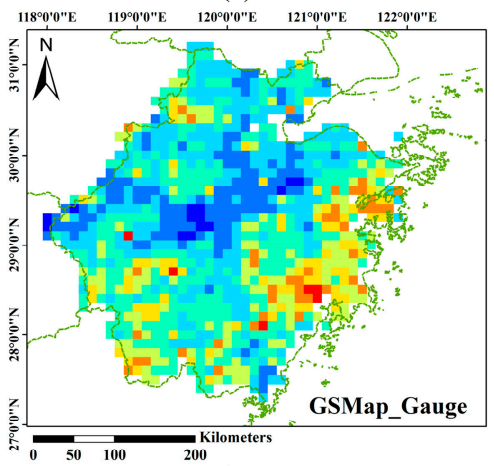

(d)

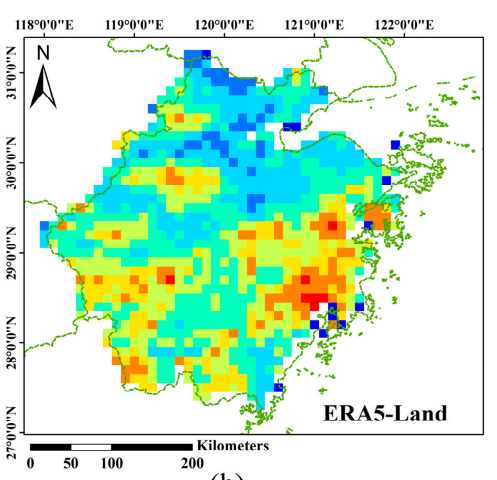

(b)

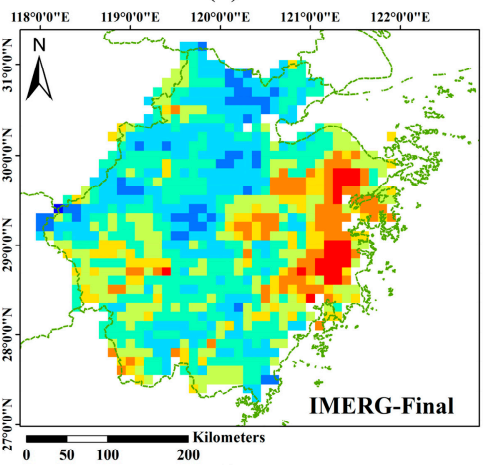

(e)

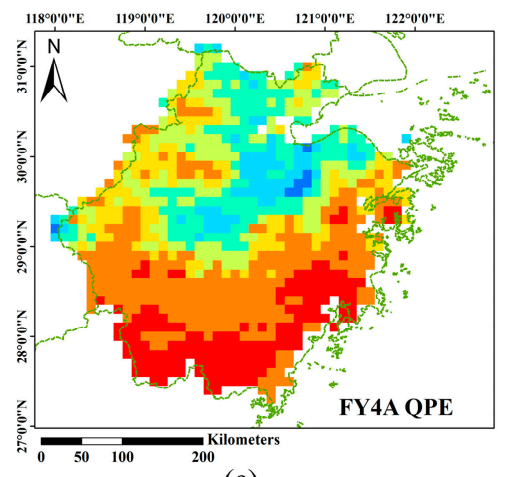

(c)

RMSE

(mm/hour)

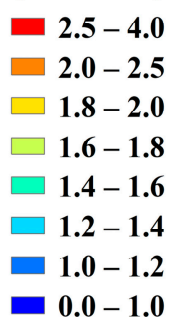

Figure 5. Spatial patterns RMSE based on (a) PERSIANN-CCS (b) ERA5-Land, (c) FY4A QPE (d) GSMap_Gauge, and (e) IMERG-Final against CMPA, at an hourly scale over the Zhejiang province in summer, from June to August 2019. 


\subsection{Temporal Patterns of Evaluations on the Precipitation Products and CMPA Data at Hourly Scale}

Based on the temporal patterns of the performances of precipitation estimates, the values of six indicators (CC, bias, RMSE, POD, FAR, and CSI) of the five precipitation products at an hourly scale in June, July, August, and summer are displayed in Table 3. The CC of all products showed that all precipitation products except ERA5-Land had stable performance in June, July, and August. For instance, the CC values of ERA5-Land in August was obviously higher than those in June and July. The FY4A QPE had the lowest values of CC with $0.22,0.26,0.21$, and 0.21 in June, July, August, and summer, respectively. While the GSMap_Gauge showed the largest CC ( 0.50) in summer and IMERG-Final had the second, which was consistent with the results obtained through spatial patterns of evaluations. In terms of bias, the bias values of all precipitation products in August were below 0\%. Specifically, the PERSIANN-CCS and FY4A QPE seriously underestimated precipitation with bias values around $-57.94 \%$ and $-83.82 \%$, respectively. In addition, the bias of PERSIANN-CCS showed that PERSIANN-CCS underestimated precipitation in all months in summer. The IMERG-Final showed the lowest bias values around $1.01 \%, 0.28 \%$, and $-4.05 \%$ in June, July, and August, respectively. In terms of RMSE, the GSMap_Gauge had the lowest values, as compared to other products, with around $1.40 \mathrm{~mm} / \mathrm{h}$ and $1.56 \mathrm{~mm} / \mathrm{h}$ in June and July, respectively, while ERA5-Land had the lowest values in August.

Table 3. Summaries of the performances of PERSIANN-CCS, ERA5-Land, FY4A QPE, GSMap_Gauge, and IMERG-Final, at an hourly scale, over Zhejiang in the summer of 2019.

\begin{tabular}{|c|c|c|c|c|c|}
\hline Index & Dataset & June & July & August & Summer \\
\hline \multirow{5}{*}{$\mathrm{CC}$} & PERSIANN-CCS & 0.24 & 0.27 & 0.29 & 0.26 \\
\hline & ERA5-Land & 0.29 & 0.32 & 0.53 & 0.39 \\
\hline & FY4A QPE & 0.22 & 0.26 & 0.21 & 0.21 \\
\hline & GSMap_Gauge & 0.51 & 0.51 & 0.49 & 0.50 \\
\hline & IMERG-Final & 0.49 & 0.51 & 0.49 & 0.48 \\
\hline \multirow{5}{*}{ bias (\%) } & PERSIANN-CCS & -26.74 & -23.74 & -57.94 & -35.03 \\
\hline & ERA5-Land & 4.91 & 15.53 & -23.11 & 0.40 \\
\hline & FY4A QPE & -4.42 & 13.57 & -83.82 & -21.68 \\
\hline & GSMap_Gauge & 1.88 & 6.92 & -7.71 & 0.82 \\
\hline & IMERG-Final & 1.01 & 0.28 & -4.05 & -0.77 \\
\hline \multirow{5}{*}{$\begin{array}{l}\text { RMSE } \\
(\mathrm{mm} / \mathrm{h})\end{array}$} & PERSIANN-CCS & 1.80 & 1.91 & 1.71 & 1.81 \\
\hline & ERA5-Land & 1.60 & 1.79 & 1.45 & 1.62 \\
\hline & FY4A QPE & 2.17 & 2.27 & 1.72 & 2.06 \\
\hline & GSMap_Gauge & 1.40 & 1.56 & 1.56 & 1.51 \\
\hline & IMERG-Final & 1.55 & 1.58 & 1.77 & 1.64 \\
\hline \multirow{5}{*}{ POD } & PERSIANN-CCS & 0.31 & 0.36 & 0.30 & 0.33 \\
\hline & ERA5-Land & 0.80 & 0.81 & 0.59 & 0.78 \\
\hline & FY4A QPE & 0.46 & 0.41 & 0.23 & 0.39 \\
\hline & GSMap_Gauge & 0.75 & 0.75 & 0.70 & 0.74 \\
\hline & IMERG-Final & 0.70 & 0.75 & 0.68 & 0.71 \\
\hline
\end{tabular}


Table 3. Cont.

\begin{tabular}{cccccc}
\hline Index & Dataset & June & July & August & \multicolumn{2}{c}{ Summer } \\
\hline \multirow{3}{*}{ FAR } & PERSIANN-CCS & 0.51 & 0.47 & 0.35 & 0.47 \\
\cline { 2 - 5 } & ERA5-Land & 0.53 & 0.55 & 0.57 & 0.54 \\
\cline { 2 - 5 } & FY4A QPE & 0.56 & 0.48 & 0.28 & 0.50 \\
\cline { 2 - 6 } & GSMap_Gauge & 0.48 & 0.48 & 0.50 & 0.48 \\
\cline { 2 - 6 } & IMERG-Final & 0.45 & 0.41 & 0.43 & 0.43 \\
\hline \multirow{3}{*}{ CSI } & PERSIANN-CCS & 0.23 & 0.27 & 0.26 & 0.25 \\
\cline { 2 - 6 } & ERA5-Land & 0.43 & 0.41 & 0.36 & 0.40 \\
\cline { 2 - 6 } & FY4A QPE & 0.29 & 0.30 & 0.21 & 0.28 \\
\cline { 2 - 5 } & GSMap_Gauge & 0.44 & 0.44 & 0.41 & 0.43 \\
\hline & IMERG-Final & 0.44 & 0.49 & 0.45 & 0.46 \\
\hline
\end{tabular}

The values of indices that evaluate the detection capability of precipitation events for five products were significantly different. It was obvious that POD of all precipitation products in August were lower than those in June and July. The ERA5-Land showed the largest values of POD in June, July, and summer, as compared to the other four products (around 0.80 in June, 0.81 in July, and 0.78 in summer), but its value in August was relatively low. While the values of POD of PERSIANN-CCS in all four periods were smaller than 0.4 , however, the FAR values of PERSIANN-CCS were not significantly smaller than other products. Though GSMap_Gauge had larger POD values than the IMERG-Final, it also had larger values of FAR than those of IMERG-Final, which directly caused the CSI values of GSMap_Gauge to be lower than those of IMERG-Final. In all, IMERG-Final performed better in detecting precipitation events than the other precipitation products, followed by GSMap_Gauge. The PERSIANN-CCS had a weak ability to judge the precipitation events.

\section{Discussion}

\subsection{Error Source Analysis of the Precipitation Product}

Figure 6 shows the numerical distributions of POD, FAR, and CSI for five precipitation products over 939 grid pixels. The values of POD of FY4A QPE were mainly from 0.2 to 0.5 and its FAR values were from 0.4 to 0.6 (Figure $6 \mathrm{a}, \mathrm{b}$ ), which were determined by the false alarm of precipitation events that mainly occurred in the Southern Zhejiang province and the missing precipitation events that mainly occurred in the north. This phenomenon might be caused by the inversion algorithm for generating the FY4A QPE, which needed to be greatly improved. In all, the hourly performances of FY4A QPE were not so satisfying. The POD of PERSIANN-CCS indicated that PERSIANN-CCS had poor abilities to capture precipitation events, even worse than FY4A QPE. In addition, the values of bias, below $0 \%$ in each month in summer, indicated PERSIANN-CCS, seriously underestimating precipitation. Meanwhile, PERSIANN-CCS might judge large number of non-rain events as light rain and light rain as non-rain events. Although it is difficult to obtain high quality inversion precipitation estimates based on infrared data, the precipitation retrieval algorithm of PERSIANN-CCS still had room to be improved.

The values of POD of ERA5-Land, GSMap_Gauge, and IMERG-Final were almost larger than 0.6 , especially the values of ERA5-Land, which were generally larger than 0.7 . However, the number of POD values that were larger than 0.5 of ERA5-Land was more than that of GSMap_Gauge and IMERG-Final (Figure 6a). The reason ERA5-Land had the largest POD values was probably because ERA5-Land is a comprehensive reanalysis precipitation product that fuses a large number of observations from multi-sources and multi-sensors, from various platforms. As for the main reasons for the variations of the POD, FAR, and CSI for the five precipitation products over the Zhejiang province, the inversion algorithms, 
observation sources, calibration procedures, orographic characteristics, and precipitation distributions might be the main factors.

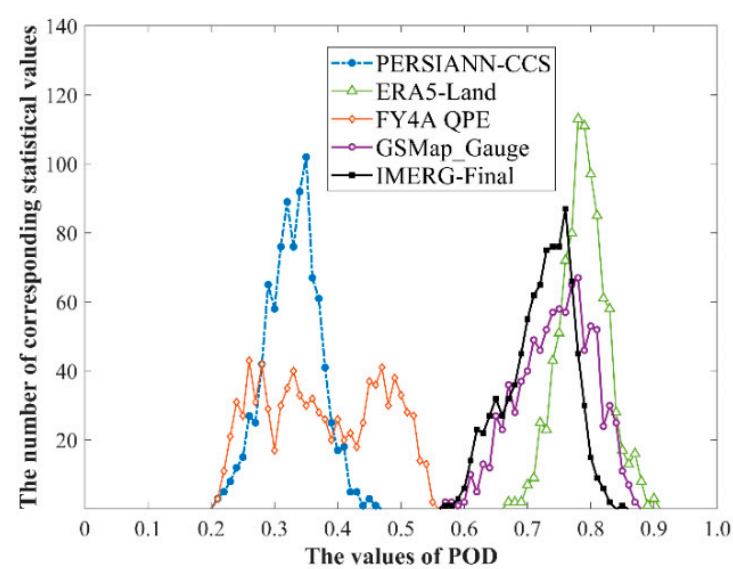

(a)

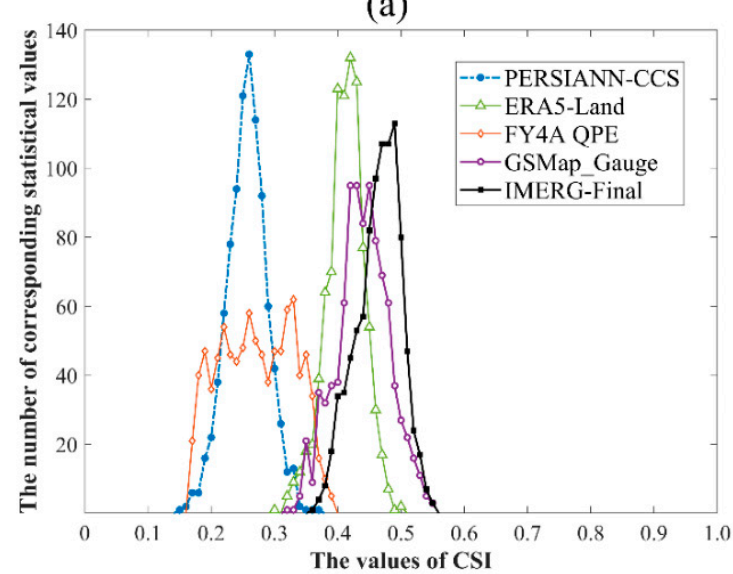

(c)

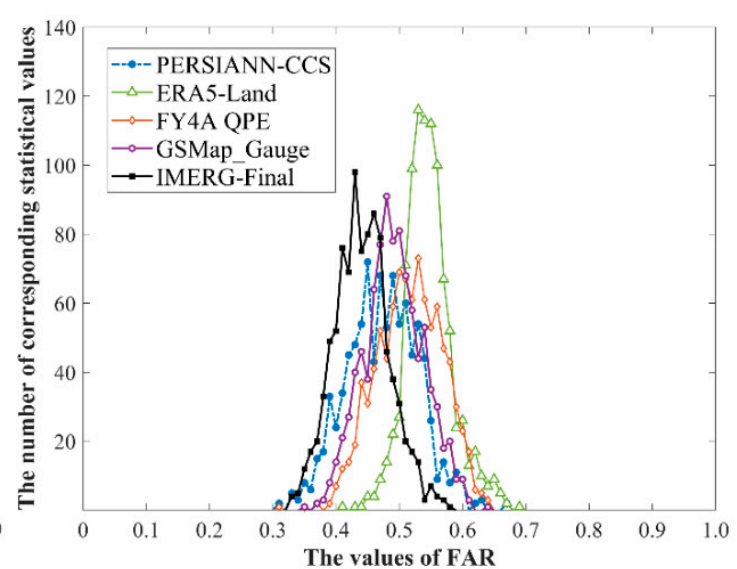

(b)

Figure 6. The numerical distributions of (a) POD, (b) FAR, and (c) CSI for the five precipitation products over the Zhejiang province in summer, from June to August 2019.

\subsection{Calibration Procedure in IMERG-Final and GSMap_Gauge}

This study showed that IMERG-Final and GSMap_Gauge data can appropriately capture precipitation events over the Zhejiang province. Considering that IMERG-Final ingests the monthly Global Precipitation Climatology Centre (GPCC) gauge analyses and that the GSMap_Gauge is calibrated by the Climate Prediction Center (CPC) daily gauge analyses, the performances had significantly improved - for instance, a slight underestimation for IMERG-Final $(-0.77 \%)$ and slight overestimation for GSMap_Gauge $(0.82 \%)$. On the one hand, the performances of GSMap_Gauge and IMERG-Final in capturing precipitation events with the values of FAR around 0.5 were not so satisfying. Therefore, how to decrease of the proportion of false alarms would be a future research work. On the other hand, the retrieving algorithms for estimating the satellite-based only precipitation products still needed to be greatly improved due to the coarse network of ground observations, especially over the remote regions, oceans, and poles.

5.3. Overall Comparisions on the Performances of the Five Precipitation Products in Summer 2018 and 2019

This study also assessed the performances of the five precipitation products in summer, from June to August 2018, to check their stabilities (Figure 7). Overall, the relative performances of the five precipitation products in summer, 2018, were consistent with those in summer, 2019. Especially in terms of occurrence detections (POD, FAR, and CSI), the 
relative performances of all five products in summer 2018 were similar to those in summer, 2019. For instance, in terms of POD, GSMap_Gauge and IMERG-Final also performed better than the others in summer, 2018, with mean values of around 0.60 and 0.59 , respectively, and the PERSIANN-CCS still performed worst, with a mean value of POD around 0.28. Similarly, in terms of FAR, ERA5-Land performed worst with the largest mean value of FAR (around 0.65) than the others, in the summer of 2018. Therefore, the evaluations on the five precipitation products provided valuable references for demonstrating the quantitative characteristics, conducted in summer, from June to August 2019.
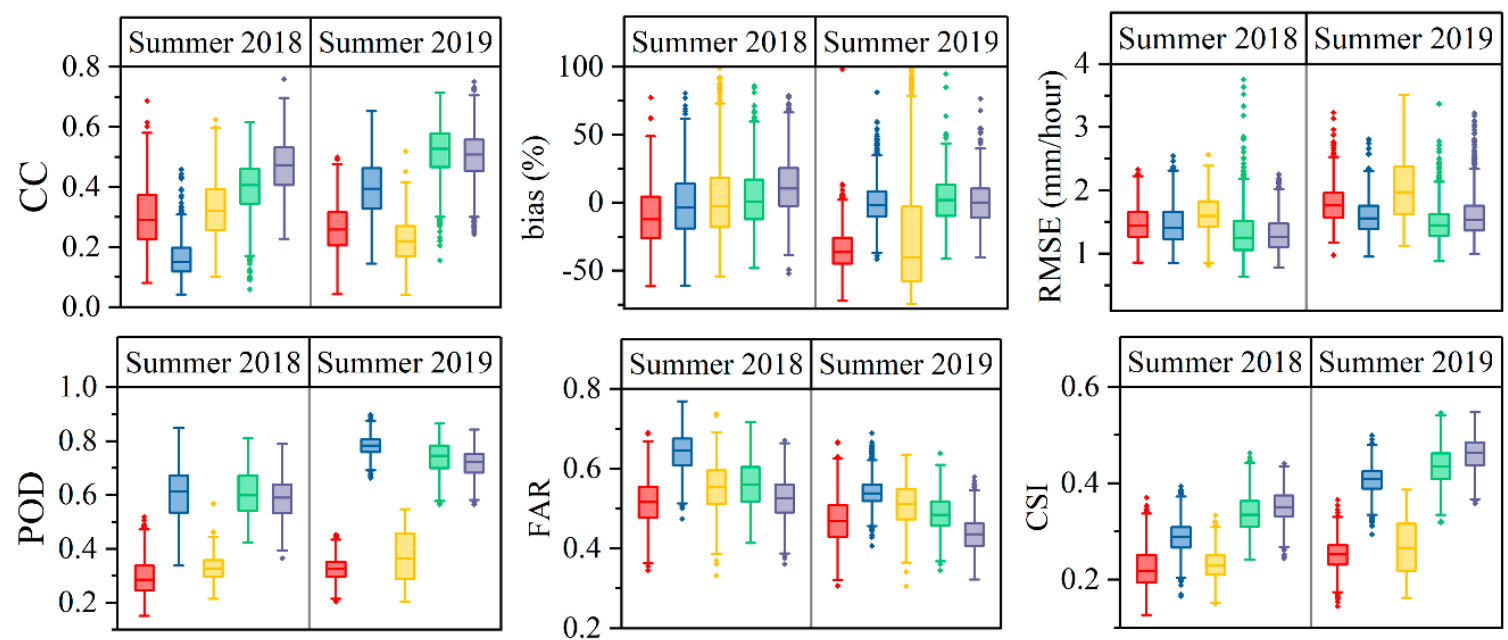

PERSIANN-CCS

ERA5-Land

FY4A QPE

GSMap_Gauge

IMERG-Final

Figure 7. Boxplots demonstrate the relative performances of CC, bias, RMSE, POD, FAR, and CSI of the five precipitation products in summer, from June to August, 2018, and 2019, respectively.

\section{Conclusions}

Precipitation data with fine quality plays vital roles in hydrological-related applications. In this study, we chose the high-quality China Merged Precipitation Analysis data (CMPA) as the benchmark for evaluating four satellite-based precipitation products (PERSIANN-CCS, FY4A QPE, GSMap_Gauge, IMERG-Final) and one reanalysis precipitation product (ERA5-Land), respectively, at $0.1^{\circ}$, hourly scales over the Zhejiang province, China, in summer from June to August 2019. The main conclusions were as follows.

(1) All other products demonstrated similar patterns with CMPA $(\sim 325.60 \mathrm{~mm} / \mathrm{h}$, std $\sim 0.07 \mathrm{~mm} / \mathrm{h})$, except FY4A QPE ( $281.79 \mathrm{~mm} / \mathrm{h}$, std $\sim 0.18 \mathrm{~mm} / \mathrm{h})$, while PERSIANNCCS overall underestimated the precipitation against CMPA with a mean value around $236.29 \mathrm{~mm} / \mathrm{h}$ (std $\sim 0.06 \mathrm{~mm} / \mathrm{h}$ ), and the ERA5-Land, GSMap_Gauge, and IMERG-Final, generally overestimated precipitation with a mean value of around $370.00 \mathrm{~mm} / \mathrm{h}$ (std $\sim 0.06 \mathrm{~mm} / \mathrm{h}$ ).

(2) The GSMap_Gauge outperformed the IMERG-Final against CMPA with CC 0.50 and RMSE $\sim 1.51 \mathrm{~mm} / \mathrm{h}$, and CC $\sim 0.48$ and RMSE $1.64 \mathrm{~mm} / \mathrm{h}$, respectively.

(3) The PERSIANN-CCS significantly underestimated precipitation (CC $\sim 0.26$, bias $\sim-35.03 \%$, RMSE $1.81 \mathrm{~mm} / \mathrm{h}$, probability of detection, POD, $\sim 0.33$, false alarm ratio, FAR, $\sim 0.47$, potentially due to its weak abilities to capture precipitation events and estimate the precipitation.

(4) Though ERA5-Land has the best ability to capture precipitation events (POD 0.78), the largest misjudgments (FAR $\sim 0.54$ ) resulted in its great uncertainties with CC $\sim 0.39$, which performed worse than those of GSMap_Gauge and IMERG-Final.

(5) The ranking of precipitation products, in terms of the general evaluation metrics, over the Zhejiang province was GSMap_Gauge, IMERG-Final, ERA5-Land, PERSIANN- 
CCS, and FY4A QPE, which provided valuable recommendations for applying these products in various related application fields.

According to the results of this study, when using these products in various hydrometeorological related application fields, we give priority to recommend GSMap_Gauge and IMERG-Final, rather than PERSIANN-CCS and FY4A QPE, over the Zhejiang province. As for the other regions, the findings of this study could provide preliminary references for related applications, while the similarities and differences of the performances of precipitation products in other regions could be further exploited. In future research, two aspects should be focused on: (1) in terms of evaluations, much more detailed error characteristics could be revealed by applying these gridded precipitation products in the spatial distributed hydrological models; and (2) more wise inversion algorithms for generating FY4A QPE should be developed by integrating the satellite-based radar observations, which was not considered at the current stage.

Author Contributions: Conceptualization: Z.M., C.Q. and L.D.; methodology, C.Q., L.D.; software, L.D. and J.X.; validation, C.Q., L.D., and L.Z.; formal analysis, C.Q. and L.D.; investigation, C.Q., L.D., and L.Z.; resources, C.Q. and L.D.; data curation, C.Q. and L.D.; writing-original draft preparation, C.Q. and L.D.; writing-review and editing, C.Q., L.D., and Z.M.; visualization, C.Q., L.D. and; supervision, Z.M.; project administration, Z.M. and C.Q.; funding acquisition, Z.M. and C.Q. All authors have read and agreed to the published version of the manuscript.

Funding: This study was financially supported by the Zhejiang Province Water science and technology project (No.RB1717); the Key R\&D Program of Ministry of Science and Technology, China (Grant No. 2018YFC1506500); Guizhou Provincial Science and Technology Plan Project ([2020] 1Y155); the Open Fund of the State Key Laboratory of Remote Sensing Science, China (Grant No. OFSLRSS201909); Research on Key Technologies of Early Warning and Forecast using Satellite-based and Ground-based Spatio-temporal data (RB2003); the State Key Laboratory of Resources and Environmental Information System, China; Research and development of real-time monitoring of water quality of large areas based on remote sensing technology (20190365).

Institutional Review Board Statement: Ethical review and approval were waived for this study, because this study did not involve humans or animals.

Informed Consent Statement: Informed consent was obtained from all subjects involved in the study.

Data Availability Statement: The data used to support the findings of this study are available from the corresponding author upon request.

Acknowledgments: The contribution of the data providers is also greatly appreciated, including the CMPA provider (http:/ / data.cma.cn), the PERSIANN-CCS provider (http://chrs.web.uci.edu/SP_ activities01.php), the ERA5-Land provider (https://cds.climate.copernicus.eu/cdsapp\#!/dataset/10 $.24381 /$ cds.e2161bac?tab=form), the FY4A QPE (www.nsmc.org.cn), the GSMap_Gauge provider (https://sharaku.eorc.jaxa.jp/GSMap/index.htm), and the IMERG-Final provider (https:/ / pmm. nasa.gov/data-access/downloads/gpm).

Conflicts of Interest: The authors declare no conflict of interest.

\section{References}

1. Ma, Z.; Ghent, D.; Han, X.; He, K.; Li, H.Y.; Han, X.Z.; Huang, Q.T.; Peng, J. Long-term Precipitation Estimates Generated by a Downscaling-calibration Procedure Over the Tibetan Plateau From 1983 to 2015. Earth Space Sci. 2019, 6. [CrossRef]

2. Ma, Z.; Xu, Y.; Peng, J.; Chen, Q.; Wan, D.; He, K.; Shi, Z.; Li, H. Spatial and temporal precipitation patterns characterized by TRMM TMPA over the Qinghai-Tibetan plateau and surroundings. Int. J. Remote Sens. 2018, 39, 3891-3907. [CrossRef]

3. Ma, Z.; Shi, Z.; Zhou, Y.; Xu, J.; Yu, W.; Yang, Y. A Spatial Data Mining Algorithm for Downscaling TMPA 3B43 V7 Data over the Qinghai-Tibet Plateau with the Effect of Systematic Anomalies Removed. Remote Sens. Environ. 2017, 200, 378-395. [CrossRef]

4. Abdelmoneim, H.; Soliman, M.; Moghazy, H. Evaluation of TRMM 3B42V7 and CHIRPS Satellite Precipitation Products as an Input for Hydrological Model over Eastern Nile Basin. Earth Syst. Environ. 2020, 4, 685-698. [CrossRef]

5. Constantinidou, K.; Hadjinicolaou, P.; Zittis, G.; Lelieveld, J. Performance of Land Surface Schemes in the WRF Model for Climate Simulations over the MENA-CORDEX Domain. Earth Syst. Environ. 2020, 4, 647-665. [CrossRef] 
6. Ehsan, M.; Almazroui, M.; Yousef, A. Impact of Different Cumulus Parameterization Schemes in SAUDI-KAU AGCM. Earth Syst. Environ. 2017, 1. [CrossRef]

7. Kidd, C.; Huffman, G. Global precipitation measurement. Meteorol. Appl. 2011, 18, 334-353. [CrossRef]

8. Jongjin, B.; Jongmin, P.; Dongryeol, R.; Minha, C. Geospatial blending to improve spatial mapping of precipitation with high spatial resolution by merging satellite-based and ground-based data. Hydrol. Process. 2016, 30, $2789-2803$.

9. Huffman, G.J.; Adler, R.F.; Bolvin, D.T.; Gu, G.; Nelkin, E.J.; Bowman, K.P.; Hong, Y.; Stocker, E.F.; Wolff, D.B. The TRMM multi-Satellite precipitation analysis (TMPA). J. Hydrometeorol. 2007, 8, 237-247.

10. Li, N.; Tang, G.; Zhao, P.; Hong, Y.; Gou, Y.; Yang, K. Statistical assessment and hydrological utility of the latest multi-satellite precipitation analysis IMERG in Ganjiang River basin. Atmos. Res. 2017, 183, 212-223. [CrossRef]

11. Ma, Z.Q.; Zhou, L.Q.; Yu, W.; Yang, Y.Y.; Teng, H.F.; Shi, Z. Improving TMPA 3B43 V7 Data Sets Using Land-Surface Characteristics and Ground Observations on the Qinghai-Tibet Plateau. IEEE Geosci. Remote Sens. Lett. 2018, 99, 1-5. [CrossRef]

12. Hong, Y.; Gochis, D.; Cheng, J.T.; Hsu, K.L.; Sorooshian, S. Evaluation of persiann-ccs rainfall measurement using the name event rain gauge network. J. Hydrometeorol. 2007, 8, 469. [CrossRef]

13. Mahrooghy, M.; Anantharaj, V.G.; Younan, N.H.; Aanstoos, J.; Hsu, K.L. On an enhanced persiann-ccs algorithm for precipitation estimation. J. Atmos. Ocean. Technol. 2012, 29, 922-932. [CrossRef]

14. Yin, R.; Han, W.; Gao, Z.; Di, D. The evaluation of fy4a's geostationary interferometric infrared sounder (giirs) longwave temperature sounding channels using the grapes global 4dar. Q. J. R. Meteorol. Soc. 2020. [CrossRef]

15. Lu, D.; Yong, B. A preliminary assessment of the gauge-adjusted near-real-time gsmap precipitation estimate over mainland china. Remote Sens. 2020, 12, 141. [CrossRef]

16. Tan, M.L.; Santo, H. Comparison of gpm imerg, tmpa $3 \mathrm{~b} 42$ and persiann-cdr satellite precipitation products over malaysia. Atmos. Res. 2018, 202, 63-76. [CrossRef]

17. Chen, S.; Tang, Z.; Wang, J. Multivariate Analysis and Geochemical Signatures of Shallow Groundwater in the Main Urban Area of Chongqing, Southwestern China. Water 2020, 12, 2833. [CrossRef]

18. Huffman, G.J.; Bolvin, D.T.; Braithwaite, D.; Hsu, K.; Joyce, R.; Kidd, C.; Nelkin, E.J.; Sorooshian, S.; Tan, J.; Xie, P. NASA Global Precipitation Measurement (GPM) Integrated Multi-satellitE Retrievals for GPM (IMERG). In Algorithm Theoretical Basis Document (ATBD); NASA/GSFC: Greenbelt, MD, USA, 2019.

19. Lu, H.; Ding, L.; Ma, Z.; Li, H.; Lu, T.; Su, M.; Xu, J. Spatiotemporal Assessments on the Satellite-Based Precipitation Products from Fengyun and GPM Over the Yunnan-Kweichow Plateau, China. Earth Space Sci. 2020, 7, e2019EA000857. [CrossRef]

20. Xu, J.; Ma, Z.; Tang, G.; Ji, Q.; Min, X.; Wan, W.; Shi, Z. Quantitative Evaluations and Error Source Analysis of Fengyun-2-Based and GPM-Based Precipitation Products over Mainland China in Summer, 2018. Remote Sens. 2019, 11, 2992. [CrossRef]

21. Mayor, Y.; Tereshchenko, I.; Fonsecahernández, M.; Pantoja, D.; Montes, J. Evaluation of error in imerg precipitation estimates under different topographic conditions and temporal scales over mexico. Remote Sens. 2017, 9, 503. [CrossRef]

22. Fu, Q.; Ruan, R.; Liu, Y. Accuracy assessment of global satellite mapping of precipitation (gsmap) product over poyang lake basin, china. Procedia Environ. Sci. 2011, 10, 2265-2271. [CrossRef]

23. Hénin, R.; Liberato, M.; Ramos, A.; Gouveia, C. Assessing the use of satellite-based estimates and high-resolution precipitation datasets for the study of extreme precipitation events over the iberian peninsula. Water 2018, 10, 1688. [CrossRef]

24. Skinner, M.W.; Kuhn, R.G.; Joseph, A.E. Agricultural land protection in china: A case study of local governance in zhejiang province. Land Use Policy 2001, 18, 329-340. [CrossRef]

25. Shen, Y.; Zhao, P.; Pan, Y.; Yu, J. A high spatiotemporal gauge-satellite merged precipitation analysis over china. J. Geophys. Res. Atmos. 2014, 119, 3063-3075. [CrossRef]

26. Yong, B.; Ren, R.L.; Hong, R.; Wang, R.H.; Gourley, R.J.; Jiang, S.H.; Chen, X.; Wang, W. Hydrologic evaluation of multisatellite precipitation analysis standard precipitation products in basins beyond its inclined latitude band: A case study in laohahe basin, china. Water Resour. Res. 2010, 46, 759-768. [CrossRef]

27. Hong, Y.; Hsu, K.; Sorooshian, S.; Gao, X. Precipitation estimation from remotely sensed imagery using an artificial neural network cloud classification system. J. Appl. Meteorol. 2004. [CrossRef]

28. Hoffmann, L.; Günther, G.L.D.; Li, D. From ERA-Interim to ERA5: The considerable impact of ECMWF's next-generation reanalysis on Lagrangian transport simulations. Atmos. Chem. Phys. 2019, 19, 3097-3124. [CrossRef]

29. Mega, T.; Ushio, T.; Matsuda, T.; Kubota, T.; Kachi, M.; Oki, R. Gauge-adjusted global satellite mapping of precipitation. IEEE Trans. Geosci. Remote Sens. 2018, 1-8. [CrossRef]

30. Tan, X.; Ma, Z.; He, K.; Han, X.; He, Y. Evaluations on gridded precipitation products spanning more than half a century over the tibetan plateau and its surroundings. J. Hydrol. 2019. [CrossRef]

31. Ma, Z.; Jin, X.; Zhu, S.; Tang, G.; Yang, Y.; Shi, Z.; Hong, Y. AIMERG: A new Asian precipitation dataset $\left(0.1^{\circ} /\right.$ half-hourly, 2000-2008) by calibrating GPM IMERG at daily scale using APHRODITE. Earth Syst. Sci. Data 2020. [CrossRef]

32. Tang, G.; Clark, M.P.; Papalexiou, S.M.; Ma, Z.; Hong, Y. Have satellite precipitation products improved over last two decades? A comprehensive comparison of GPM IMERG with nine satellite and reanalysis datasets. Remote Sens. Environ. 2020, $240,111697$. [CrossRef] 